\title{
PENGARUH MASASE DENGAN TERAPI PANAS TERHADAP PEMULIHAN GANGGUAN NYERI OTOT TRAPEZIUS PADA PEMAIN RUGBY
}

\author{
Gilang Fachri Maulana ${ }^{1}$, Ali Satia Graha ${ }^{1}$ \\ ${ }^{1}$ Fakultas Ilmu Keolahragaan, Universitas Negeri Yogyakarta, Jl. Colombo No. 1, Karangmalang Depok, \\ Sleman, Yogyakarta, Indonesia \\ gilang6358fik2015@student.uny.ac.id, ali_satiagraha@uny.ac.id
}

\begin{abstract}
Abstrak
Olahraga rugby merupakan olahraga intensitas tinggi yang ditandai dengan adanya aktivitas lari dengan kecepatan tinggi, sprint, dan hantaman-hantaman antar pemain. Gangguan nyeri otot trapezius sering terjadi pada pemain rugby. Tujuan penelitian ini adalah untuk mengetahui adanya pengaruh masase dengan terapi panas terhadap pemulihan gangguan nyeri otot trapezius pada pemain rugby. Penelitian ini merupakan penelitian pre-experimental dengan rancangan one group pretest-posttest design. Populasi dalam penelitian ini adalah pemain rugby Universitas Negeri Yogyakarta. Teknik pengambilan sampel menggunakan purposive sampling dengan kriteria inklusi dan eksklusi sehingga didapatkan sampel sebanyak 10 orang. Data yang dikumpulkan adalah derajat nyeri otot trapezius sebelum dan sesudah perlakuan sebanyak 6 sesi. Teknik analisis data menggunakan analisis deskriptif dan uji hipotesis dengan Wilcoxon Signed Rank Test. Hasil penelitian menunjukkan bahwa ada pengaruh masase dengan terapi panas terhadap pemulihan gangguan nyeri otot trapezius. Penelitian ini menunjukkan bahwa terdapat penurunan nilai nyeri pada sebelum perlakuan (pretest) dan setelah perlakuan (posttest) pada setiap sesi. Walaupun demikian, persepsi nyeri mengalami kenaikan kembali pada setiap sesi sebelum diberikan perlakuan.
\end{abstract}

Kata kunci: masase, terapi panas, gangguan nyeri otot trapezius

\section{THE EFFECT OF MASSAGE WITH HEAT THERAPY ON THE RECOVERY OF TRAPEZIUS MUSCLE PAIN DISORDERS IN RUGBY PLAYERS}

\begin{abstract}
Rugby is a high-intensity sport characterized by high-speed running, sprinting, and collision between players. Trapezius muscle pain disorders often occur in rugby players. The purpose of this study was to determine the effect of massage with heat therapy on the recovery of trapezius muscle pain disorders in rugby players. This research is a pre-experimental research with one group pretest-posttest design. The population in this study is the rugby player of Yogyakarta State University. The sampling technique uses purposive sampling with inclusion and exclusion criteria so that a sample of 10 people is obtained. Data collected was the degree of trapezius muscle pain before and after treatment for 6 sessions. Data analysis techniques used descriptive analysis and hypothesis testing with the Wilcoxon Signed Rank Test. The results showed that there was an effect of massage with heat therapy on the recovery of trapezius muscle pain disorders. This study shows that there is a decrease in the value of pain before and after the treatment (posttest) at each session. However, the perception of pain has increased again in each session before being given treatment.
\end{abstract}

Keywords: massage, heat therapy, trapezius muscle pain disorders 


\section{PENDAHULUAN}

Olahraga rugby merupakan olahraga dengan intensitas yang tinggi. Para pemain rugby dituntut untuk memiliki performa fisik yang sangat kuat. Olahraga ini merupakan olahraga yang rentan akan kontak fisik dan benturan-benturan keras, sehingga potensi pemain untnuk mengalami cedera sangat tinggi. Terdapat 1841 kasus cedera pada 1159 pemain muda umur 13 hingga 21 tahun yang berpartisipasi pada tim sekolah dan klub dalam musim 2002 hingga 2003, di antaranya terdapat 96 cedera leher dan 21 di antaranya terjadi di luar pertandingan (McIntosh, 2015: 189). Cedera yang paling sering terjadi padaolahraga rugby ialah pada saat benturan langsung pada tackling (Usman, 2014: 4).।

Otot yang bekerja dalam menahan benturan ketika tackling menggunakan bahu adalah otot trapezius (Stastny, 2016: 190). Benturan langsung dan cedera pada otot trapezius pada permainan rugby biasa terjadi (Beer, 2009: 1). Penggunaan otot trapezius yang berlebihan, sering, dan terus-menerus akan menyebabkan ketegangan, spasme, tightness, dan stiffness sehingga akan timbul nyeri pada otot trapezius (Purnama, 2018: 72). Terapi fisik merupakan teknik pengobatan dengan modalitas fisik yang dapat dilakukan menggunakan listrik, suara, panas, dingin, magnet, tenaga gerak, dan air (Arovah, 2016: 2). Berbagai macam terapi fisik, seperti terapi manipulatif, terapi latihan, akupuntur, dan terapi listrik dapat dilakukan untuk perawatan cedera otot. Salah satu perawatan yang dilakukan dalam melaksanakan terapi manipulatif dengan tujuan untuk mengurangi nyeri ialah terapi masase (Ho, 2009: 463). Terapi masase adalah salah satu penanganan nyeri otot yang umum dilakukan. Pemijatan atau massage dapat memperbaiki masalah di persendian otot, melenturkan tubuh, memulihkan ketegangan dan meredakan nyeri (Triyadini, 2010: 175). Ada hubungan antara penurunan tingkat nyeri setelah terapi masase dan perbedaan signifikan pada skor nyeri sebelum dan sesudah terapi masase (Adams, 2010: 9). Terapi masase memiliki manfaat jangka pendek pada nyeri bahu pada efek lanjut (Kong, 2013: 7).

Modalitas terapi fisik yang banyak digunakan untuk penanganan nyeri ialah terapi menggunakan suhu dingin dan panas. Terapi dingin bermanfaat dalam mengurangi nyeri akut dan terapi panas bermanfaat adalam mengurangi nyeri kronis pada otot (Corti, 2014: 24). Terapi panas dan dingin merupakan perawatan standar untuk penanganan nyeri muskuloskeletal akut. Namun, kebanyakan rekomendasi penggunaan panas dan dingin pada penanganan nyeri muskuloskeletal akut hanya berdasarkan pengalaman empiris karena terbatasnya bukti yang mendukung. Panas dan dingin membantu dalam penanganan nyeri otot, tapi panas terlihat lebih shahih (Malanga, 2015: 62). Salah satu cara penanganan nyeri dengan terapi panas ialah dengan kompres panas. Kompres panas dapat digunakan pada penanganan nyeri dan merelaksasikan otot-otot yang tegang (Dahlan, 2017: 42). Kompres panas memiliki sifat vasodilatasi yang meredakan nyeri dengan cara merelaksasikan otot (Felina, 2015:62).

\section{METODE}

Jenis penelitian ini adalah pre-experimental dengan bentuk penelitian one group pretestpostest design. Subjek penelitian ini adalah pemain rugby UNY laki-laki yang mengalami gangguan nyeri otot trapezius setelah latihan. Penentuan diagnosa nyeri otot trapezius dilakukan dengan skala numerik.

Subjek penelitian hanya ada 1 kelompok, yaitu kelompok penelitian yang diberi perlakuan berupa masase dengan terapi panas. Subjek penelitian diberikan angket derajat nyeri untuk pemeriksaan awal (pretest) dan pemeriksaan akhir (posttest) pada saat sebelum dan sesudah diberi perlakuan (treatment).

Populasi pada penelitian ini ialah para pemain rugby UNY sebanyak 39 orang. Sampel pada penelitian ini ialah para pemain rugby UNY yang mengalami gangguan nyeri otot trapezius. Teknik pengambilan sampel menggunakan teknik purposive sampling dengan kriteria inklusi, yaitu (1) Laki-laki, (2) Aktif berlatih, (3) mengalami gangguan nyeri pada otot 
trapezius; dan kriteria eksklusi, yaitu (1) Terdapat fraktur pada tulang penyusun sendi bahu, (2) Terdapat strain grade 3 pada otot trapezius, (3) Terdapat luka terbuka pada otot trapezius, (4) Ada tanda-tanda peradangan akut. Jumlah subjek yang masuk dalam kriteria inklusi sebanyak 10 orang.

\section{Teknik Pengumpulan Data}

(1) Peneliti meminta izin untuk melakukan pengambilan data penelitian kepada sampel yang merupakan pemain rugby UNY dengan membawa surat izin penelitian. (2) Peneliti menentukan sejumlah sampel penelitian dari populasi, dan diperoleh sejumlah 10 sampel penelitian. (3) Sampel penelitian diberikan pengarahan terkait petunjuk teknis pengisian informed consent (lembar kesediaan menjadi sampel penelitian) dan waktu penelitian.(3) Peneliti memberikan instrumen penelitian berupa lembar SOP masase dengan terapi panas kepada masseur dan standar skala numerik kepada sampel.(3) Peneliti mengambil data pretest kepada sampel sejumlah 10 orang. Data yang diambil berupa nilai derajat nyeri otot trapezius sebelum diberikan perlakuan masase dengan terapi panas sebanyak 6 sesi (1 kali setiap sesi).(4) Sampel penelitian diberi perlakuan berupa masase dengan terapi panas sesuai SOP sebanyak 6 sesi (1 kali setiap sesi).(5) Peneliti mengambil data posttest kepada sampel sejumlah 10 orang. Data yang diambil berupa nilai derajat nyeri otot trapezius setelah diberikan perlakuan masase dengan terapi panas sebanyak 6 sesi (1 kali setiap sesi). (6) Peneliti mengumpulkan seluruh data mentah hasil pengukuran, kemudian diolah menggunakan SPSS.

\section{Instrumen Pengumpulan Data}

Instrumen yang digunakan dalam penelitian ini adalah alat-alat yang digunakan untuk mendapatkan hasil derajat nyeri pada otot trapezius, yaitu: (1) Numeric Rating Scale (NRS) atau Skala Numerik yang dimodifikasi. Numeric Rating Scale (NRS) atau Skala Numerik yang memiliki skor 0 sampai 10. Beberapa skala pada Numeric Rating Scale (NRS) yang dimodifikasi ini dapat diklasifikasikan sebagai berikut: 1) Skala 0 : tidak nyeri ,2) Skala 1-3 : nyeri ringan, 3) Skala 4-6 : nyeri sedang, 4) Skala 7-9 : nyeri berat, 5) Skala 10 : nyeri terberat yang dirasakan. (2) Panduan atau Standar Operasional Prosedur (SOP) masase dengan terapi panas, standar Operasional Prosedur (SOP) masase dengan terapi panas digunakan sebagai panduan masseur dalam memberikan perlakuan masase dengan terapi panas pada subjek penelitian.

\section{Teknik Analisis Data}

Analisis data deskriptif adalah cara menggambarkan data yang telah terkumpul sebagaimana adanya tanpa bermaksud membuat kesimpulan yang berlaku untuk umum. Adapun tujuan dari deskriptif ini adalah untuk membuat deskripsi atau gambaran hubungan antar fenomena yang diselidiki. Data yang dianalisis adalah data pretest dan posttest pada setiap sesi.

\section{HASIL DAN PEMBAHASAN}

\section{Hasil Deskriptif}

Pengukuran persepsi nyeri dilakukan dengan menggunakan Numeric Rating Scale (NRS) dengan angka 0-10. Data yang dianalisis ialah persepsi nyeri sebelum perlakuan (pretest) dan persepsi nyeri setelah perlakuan (posttest). Berdasarkan hasil analisis deskriptif di atas, dapat diketahui bahwa dengan jumlah sampel sebanyak 10 orang, rata-rata persepsi nyeri sebelum perlakuan (pretest) tertinggi ditemukan pada sesi perlakuan 2 (7.10) dan terendah pada sesi perlakuan 6 (6.00). Nilai rata-rata persepsi nyeri setelahperlakuan (posttest) tertinggi ditemukan pada sesi perlakuan 1 (5.10) dan terendah pada sesi perlakuan 6 (2.90). Terlihat bahwa perbedaan tingkat nyeri rata-rata sebelum dan sesudah perlakuan pada sesi 1 belum sebesar sesi selanjutnya. Terlihat pula besaran penurunan persepsi nyeri cenderung konstan pada sesi 2 hingga sesi 6. Gambar di atas juga menunjukkan bahwa persepsi nyeri rata-rata sebelum 
perlakuan (pretest) cenderung menurun dimulai dari sesi 2 hingga sesi 6 , sedangkan persesi nyeri rata-rata sesudah perlakuan (posttest) terus menurun sejak sesi 1 sampai sesi 6 .

Persepsi nyeri pada numeric rating scale ini dikelompokkan menjadi 5 klasifikasi, yaitu tidak nyeri, nyeri ringan, nyeri sedang, nyeri berat, dan nyeri terberat yang dirasakan. Persentase derajat nyeri pada otot trapezius dengan jumlah sampel sebanyak 10 orang pada setiap sesi dapat diketahui bahwa dengan jumlah sampel sebanyak 10 orang terdapat perbedaan persentase pada setiap kategori antara sebelum perlakuan (pretest) dan setelah perlakuan (posttest) masase dengan terapi panas terhadap gangguan nyeri otot trapezius pada setiap sesi. Berdasarkan tabel di atas, dapat dilihat bahwa secara konsisten terjadi pergeseran distribusi nyeri 'berat' dan golongan nyeri 'terberat yang dirasakan' ke arah nyeri sedang dan ringan. Walaupun demikian, hingga dengan akhir perlakuan sesi 6 belum ada partisipan yang tidak merasakan nyeri.

\section{PEMBAHASAN}

Berdasarkan pada hasil penelitian di atas, dapat diketahui bahwa masase dengan terapi panas memiliki pengaruh terhadap pemulihan gangguan nyeri otot trapezius. Penelitian ini menunjukkan bahwa terdapat penurunan nilai nyeri pada sebelum perlakuan (pretest) dan setelah perlakuan (posttest) pada setiap sesi. Walaupun demikian, persepsi nyeri mengalami kenaikan kembali pada setiap sesi sebelum diberikan perlakuan. Derajat nyeri pada sebelum perlakuan sesi 1 (pretest_1) dan sebelum perlakuan sesi 2 (pretest_2) juga mengalami kenaikan, walaupun pada sesi 1 derajat nyeri mengalami penurunan setelah diberi perlakuan. Ini membuktikan bahwa perlakuan pada sesi 1 belum mengakibatkan pengaruh jangka panjang hingga ke sesi 2 .

Lebih lanjut terlihat bahwa persepsi nyeri sebelum perlakuan sesi 2 (pretest_2) hingga sebelum perlakuan sesi 6 (pretest_6) mengalami penurunan. Ini membuktikan bahwa perlakuan pada sesi 2 mulai mengakibatkan pengaruh jangka panjang hingga sesi 6 . Walaupun demikian, penurunan persepsi nyeri yang terjadi pada setiap sesi perlakuan meningkat kembali pada sesi perlakuan berikutnya. Hal ini menunjukkan bahwa diperlukan lebih dari 6 sesi perlakuan (dalam periode waktu 2 minggu) agar persepsi nyeri menjadi berkurang secara permanen.

Pemberian masase pada otot trapezius dapat membantu mengendorkan ketegangan otot, merangsang serabut-serabut saraf agar relaks, meningkatkan kelancaran peredaran darah, serta mengurangi rasa nyeri dan mempercepat proses regenerasi. Masase merupakan salah satu penyembuhan dengan menggunakan sentuhan untuk merangsang produksi bahan kimia tertentu dalam sistem kekebalan yang mendorong penyembuhan. Masase dapat merelaksasi otot dan melepaskan penumpukan asam laktat yang terakumulasi selama latihan, meningkatkan sirkulasi darah dan getah bening, meregangkan sendi, serta meringankan rasa sakit.

Pemberian terapi panas pada otot trapezius dapat membantu mengurangi spasme otot, mengurangi persepsi nyeri, meningkatkan aliran darah, dan meningkatkan kecepatan metabolisme pada tubuh. Efek fisiologis terapi panas dalam mengurangi rasa nyeri, yaitu dengan mempromosikan relaksasi otot, meningkatkan sirkulasi, mempromosikan relaksasi psikologis dan perasaan nyaman

\section{SIMPULAN}

Berdasarkan hasil penelitian dan pembahasan, maka dapat diambil simpulan bahwa ada pengaruh masase dengan terapi panas terhadap pemulihan gangguan nyeri otot trapezius pada pemain rugby UNY. Bagi peneliti agar dapat mengembangkan penelitian ini dalam hal membandingkan antara pengaruh masase dan terapi panas terhadap pemulihan gangguan nyeri otot trapezius. Bagi peneliti agar dapat mengembangkan penelitian-penelitian lain dalam hal memulihkan gangguan nyeri otot trapezius dengan menggunakan perlakuan-perlakuan lain agar dapat menghasilkan pemulihan yang lebih efektif dan efisien. Bagi masseur atau terapis 
agar dapat mengaplikasikan metode-metode pemulihan gangguan nyeri otot secara lebih cepat dan tepat. Bagi tim rugby agar dapat menambah wawasan dalam hal pemulihan gangguan nyeri otot dan menggunakan hasil-hasil penelitian dalam hal memulihkan gangguan-gangguan nyeri otot.

\section{DAFTAR PUSTAKA}

Adams, Rose., White, Barb. \& Beckett, Cynthia. (2010). The Effects of Massage Therapy on Pain Management in The Acute Care Setting. International Journal of Therapeutic Massage and Bodywork, 3 (1), 4-11.

Arovah, Novita Intan. (2016). Fisioterapi Olahraga. Jakarta: Penerbit Buku Kedokteran EGC.

Beer, Joe de. \& Bhatia, Deepak N. (2009). Shoulder Injuries in Rugby Players. International Journal of Shoulder Surgery, 3 (1), 1-3.

Corti, Lisa. (2014). Non-Pharmaceutical Approaches to Pain Management. Topics in Companion Animal Medicine, 29 (1), 24-38.

Felina, Mutia., Masrul. \& Iryani, Detty. (2015). Pengaruh Kompres Panas dan Dingin terhadap Penurunan Nyeri Kala I Fase Aktif Persalinan Fisiologis Ibu Primipara. Jurnal Kesehatan Andalas, 4 (1), 58-64

Ho, Chung-Yee Cecilia., Sole, Gisela. \& Munn, Joanne. (2009). The Effectiveness of Manual Therapy in The Management of Musculoskeletal Disorders of The Shoulder: A Systematic Review. Manual Therapy, 14 (5), 463-474.

Kong, Ling Jun, Zhan, Hong Sheng., Cheng, Ying Wu., et al. (2013). Massage Therapy for Neck and Shoulder Pain: A Systematic Review and Meta-Analysis. Evidence-Based Complementary and Alternative Medicine, 2013. 1-10.

Malanga, Gerard A., Yan, Ning. \& Stark, Jill. (2015). Mechanisms and Efficacy of Heat and Cold Therapies for Musculoskeletal Injury. Postgraduate Medicine, 127 (1), 57-65.

McIntosh, Andrew Stuart., McCroyu, Paul., Finch, Caroline F. (2010). Head, Face, and Neck Injury in Youth Rugby: Incidence and Risk Factors. British Journal of Sports Medicine, 44 (3), 188-193.

Purnama, Yugi Hari Chandra. (2018). Pengaruh Bekam terhadap Penurunan Nyeri pada Klien dengan Trapezius Myalgia pada Pekerja Angkut di Kecamatan Jelbuk Jember. The Indonesian Journal of Health Science, Edisi Khusus, 66-76.

Stastny, Petr., Bacakova, Radka., Chytilova, Martina., et al. (2016). The Differences in Shoulder Muscle Activity between Injured and Uninjured Rugby Players During Playerand Bag- Tackling. Trends in Sport Sciences, 4 (23), 185-191.

Triyadini., Asrin. \& Utomo, Arif Setyo. (2010). Efektifitas Terapi Massage dengan Terapi Mandi Air Hangat terhadap Penurunan Insomnia Lansia. Jurnal Keperawatan Soedirman, 5 (3), 174-181.

Usman, Juliana., McIntosh, Andrew S., Quarrie, Kenneth., et al. (2014). Shoulder Injuries in Elite Rugby Union Football Matches: Epidemiology and Mechanisms. Journal of Science and Medicine in Sport. 18 (5), 529-533. 